\title{
Acceso a la Justicia y Defensa Pública en Contextos Federales: ¿Quién accede y por qué en las provincias argentinas?*
}

Access to Justice and Public Defense in Federal Contexts: who accesses

and why in the argentinian provinces?

\section{CATALINA SMULOVITZ}

Departamento de Ciencia Política y Estudios Internacionales,

Universidad Torcuato Di Tella, Argentina

Consejo Nacional de Investigaciones Científicas y Técnicas

smulovitz@utdt.edu

El artículo compara la forma en que las provincias argentinas prestan servicios jurídicos gratuitos y analiza los factores que explican las diferencias en su provisión. Se argumenta que la provisión de defensa pública y el acceso a la justicia resultan muy heterogéneas entre jurisdicciones debido a que el federalismo argentino otorga a las provincias amplias capacidades legislativas para definir el sistema legal local. El artículo describe la variación en la forma en la que las provincias proveen defensa pública y analiza si la misma es atribuible a consideraciones administrativas, a necesidades de la población local, a la oferta de abogados privados o a los niveles de competencia política. Los resultados empíricos muestran que la forma en que las provincias proveen defensa pública no está relacionada con las necesidades de la población, sino con consideraciones administrativas y con el tamaño del mercado local de abogados privados.

\section{Introducción**}

La igualdad ante la ley es una poderosa y estimulante promesa de la democracia. Sin embargo, diferencias en la distribución de recursos sociales, políticos y económicos de los actores generan desigualdades en el acceso a la justicia y consecuentemente en la resultante protección de derechos (Galanter, 1974; Cappelletti y Garth, 1978). Más allá del indiscutible efecto de estas variables sobre el acceso y la protección, existe otro elemento, habitualmente ignorado, que también tiene consecuencias sobre la provisión de

* $\quad$ Este artículo modifica y actualiza una versión en inglés publicada en Smulovitz (2019).

** La autora agradece los aportes de dos evaluadores anónimos de Revista SAAP, a una versión previa de este artículo. Agradezco la rigurosa asistencia de investigación de Catalina Marino y de Andrés Miño. Por supuesto, los errores siguen siendo míos. 
defensa pública: el diseño institucional de los regímenes federales. Observaciones preliminares muestran que en países con instituciones federales el acceso a la justicia y la implementación de derechos varía entre unidades subnacionales (O’Donnell, 1993; Dulitzky, 2007). Esto es, países en donde jurisdicciones subnacionales con requisitos de acceso poco exigentes conviven con otras en donde las barreras de acceso son difíciles de superar.

El artículo compara la forma en que las provincias argentinas prestan servicios jurídicos gratuitos y analiza los factores que explican las diferencias en su provisión. Sostiene, en primer lugar, que en tanto el diseño institucional del federalismo argentino otorga a las provincias amplias capacidades legislativas que las habilitan a redefinir y precisar aspectos relevantes del sistema legal local, la provisión de defensa pública y el acceso a la justicia resultan muy heterogéneas entre jurisdicciones. Por otro lado, y luego de describir las diferencias en las formas en las que las provincias proveen defensa pública, el artículo analiza si dichas diferencias son atribuibles a variables administrativas como el tamaño de la población o de la superficie provincial; a variables relacionadas con las necesidades de la población local como la pobreza o los niveles de litigiosidad o a variables relacionadas con la oferta local de abogados privados, o los niveles de competencia política provincial. En este trabajo se muestra que las diferencias en la forma en que las provincias proveen defensa pública está relacionada con una de las variables administrativas (tamaño de la población), y con el tamaño del mercado local de abogados privados, y que las consideraciones relacionadas con las necesidades de la población, tales como los niveles de pobreza y litigiosidad local, no parecen tener impacto sobre la forma, oferta e inversiones en defensa pública que las mismas hacen.

El artículo dialoga con dos debates conceptuales relevantes. En primer lugar, y en relación a las discusiones sobre federalismo, el artículo confirma, con nueva evidencia empírica, que como señalaba Wildavsky (1985) «el federalismo significa desigualdad». En particular, muestra que al analizar el impacto del federalismo en las políticas públicas se debe considerar no solo las consecuencias del poder fiscal sino también la distribución de las capacidades legislativas entre el gobierno central y las jurisdicciones subnacionales. El trabajo también dialoga con los debates que analizan los determinantes del acceso a la justicia y a la defensa legal gratuita. En relación a este tema, se muestra que el acceso a la justicia depende no sólo de los recursos sociales, económicos y organizacionales de los actores, sino también de la forma en que el diseño institucional federal establece quiénes definen y cómo el contenido y la implementación de derechos en los distritos subnacionales. Si la definición del acceso a la justicia y a la defensa pública depende del distrito, entonces, el lugar en donde se ejerce un derecho se convierte en un elemen- 
to central en la definición de la política y en una eventual fuente de desigualdad. Cuando el acceso a la justicia y a la defensa pública depende del lugar físico en donde los demandantes de justicia están localizados entonces, qué jurisdicción decide y sobre qué, pasan a ser temas centrales en las discusiones sobre desigualdad y acceso.

Existen pocos, pero relevantes trabajos que analizan el comportamiento de los Tribunales Superiores provinciales (Bill Chavez, 2004; Castagnola, 2010; Abdulhadi,2016; 2019) y los poderes judiciales subnacionales (Bergoglio, 2007). Sin embargo, la literatura politológica local no ha estudiado las oficinas subnacionales que proveen defensa pública. Esta falta de interés no es irrelevante en tanto implica dejar de lado aquellas áreas del poder judicial que, ya sea por el volumen y tipos de casos que trata, como por las características de la población que las utiliza, inciden significativamente en la vida cotidiana y rutinaria de los ciudadanos. Entre el año 2000 y 2013, por ejemplo, entre el $76 \%$ y $82 \%$ de la actividad judicial de la Argentina tuvo lugar en las judicaturas provinciales (Garavano, 2011; JUFEJUS, 2010) y entre 2004 y 2007 , en algunas provincias entre el 30 y el 80 por ciento de los casos que trataban los tribunales provinciales penales requirieron de la participación de defensores públicos (Smulovitz, 2019). Sin embargo, ya sea porque es más difícil acceder a la información sobre su funcionamiento o porque se supone que tratan cuestiones de menor relevancia política, suele dejarse de lado el estudio de los tribunales inferiores provinciales. Como consecuencia de esta decisión se pierde de vista el estudio de los tribunales en los que tiene lugar la mayor parte de la actividad judicial en la Argentina y las instancias judiciales que los individuos más utilizan en sus interacciones cotidianas y rutinarias con la ley.

El artículo se organiza de la siguiente manera. La próxima sección analiza por qué las oficinas de defensores públicos importan para garantizar el acceso a los tribunales y a la justicia. La siguiente estudia cómo se relaciona el diseño institucional federal con la desigualdad legal, y con la desigual distribución de defensores públicos en el territorio. La cuarta sección examina las normas «de jure» que caracterizan a los sistemas de defensa pública provincial y los determinantes políticos y sociales que definen la accesibilidad de los mismos en las provincias. El análisis revela altos niveles de heterogeneidad en la forma en que las provincias ofrecen defensa pública a sus ciudadanos. La siguiente sección muestra 1) que la «generosidad» formal de los regímenes provinciales de defensa pública no se correlaciona con la oferta local de defensores públicos, 2) que los esfuerzos provinciales por brindar servicios de defensa pública están determinados por consideraciones burocráticas, especialmente por las dimensiones de la población provincial, y por consideraciones corporativas, como el tamaño del mercado local de 
abogados, y no por las necesidades de la población que requiere el servicio. Finalmente, la última sección concluye con algunas consideraciones respecto del impacto que la estructura federal tiene sobre la igualdad legal y sugiere algunas ideas para investigaciones futuras.

\section{Acceso a la Justicia y a los Servicios de Defensa Pública}

¿Por qué el acceso a servicios de representación jurídica gratuita importa para el funcionamiento de la democracia? El acceso a la justicia indica no solo si existe igualdad ante la ley sino también si aquellos que poseen menos recursos estarán en condiciones de controlar a sus gobernantes y de protegerse frente a actos arbitrarios. Si los mecanismos institucionales no garantizan el acceso o si no existe efectiva provisión de servicios jurídicos gratuitos, los ciudadanos más débiles o con menores recursos no podrán defenderse y tampoco podrán aspirar a fiscalizar a sus gobernantes. Sin mecanismos que aseguren acceso a la justicia, la igualdad ante la ley y el estado de derecho se debilitan. La cuestión del acceso no se restringe a la facilidad para acceder a los tribunales o a la disponibilidad de defensores públicos, también implica preguntarse quiénes son los actores legitimados para reclamar y sobre qué tipo de cuestiones se lo puede hacer. Aun cuando la cuestión del acceso a la justicia es más amplia que la pregunta por el acceso a los tribunales, en este artículo solo me concentraré en el análisis de la disponibilidad y acceso a los servicios gratuitos de defensa pública.

Sabemos que el acceso a las instituciones judiciales depende de factores económicos, institucionales, psicológicos e informativos (Galanter, 1974; Cappelletti y Garth, 1978). Las barreras económicas se relacionan con los honorarios de los abogados y con los costos del litigio. Las barreras psicológicas e informativas se refieren a la distancia social entre los acusados y las instituciones judiciales, al conocimiento que los acusados tienen de sus derechos y de los procedimientos jurídicos, como así también a las barreras lingüísticas que en algunos casos afectan a las poblaciones que necesitan relacionarse con el sistema jurídico. Finalmente, los obstáculos institucionales comprenden cuestiones tales como la distribución geográfica de los tribunales, los requisitos formales que deben cumplirse para presentar casos (Wilson y Rodriguez Cordero, 2006), la mora en la resolución de los casos y la complicada jerga utilizada por los agentes del sistema judicial. Asimismo, cabe agregar que la literatura sobre «la revolución de los derechos» señala que la posibilidad de reclamar y proteger derechos ante los tribunales también depende de la oferta de plataformas de apoyo, esto es, de la existencia de abogados y de organizaciones dedicadas a la defensa de derechos (Galanter, 
1974; Epp, 1998). Diversos estudios empíricos muestran que en la mayoría de los países la asistencia de los abogados continúa siendo obligatoria para presentar demandas ante la corte y también que los resultados de los litigios tienden a mejorar cuando los acusados cuentan con alguna forma de asistencia legal (Kritzer y Silbey, 2003). En consecuencia, aun cuando la disponibilidad de servicios jurídicos gratuitos es solo una de las dimensiones del acceso a la justicia, continúa siendo un aspecto extremadamente relevante del problema.

En la actualidad, la asistencia legal para poblaciones de escasos recursos se brinda a través de tres sistemas principales (Rhode, 2004; Lopez Puleio, 2002; Pérez-Perdomo, 2003). El «sistema honorífico» implica la obligación de los abogados a defender, en forma gratuita, a aquellos que no puedan contratar a un abogado debido a su condición socioeconómica. En este sistema, los tribunales eligen un abogado para representar al acusado en un caso particular, y la obligación del abogado deriva del código de ética de la profesión. La provisión del servicio depende de la decisión del tribunal de nominar a un abogado y de la disposición del abogado por prestar el servicio adecuadamente. Dado que los abogados designados no reciben honorarios por este servicio, no siempre dedican el tiempo y los esfuerzos suficientes a los casos que les han sido asignados. El segundo sistema, denominado «burocrático», supone la creación de agencias estatales con abogados asalariados, que prestan servicios jurídicos gratuitos a poblaciones de menores recursos. En este sistema, presente en varios países latinoamericanos, los acusados no necesariamente confían en sus abogados designados, ya que los perciben como empleados del mismo Estado que a su vez está a cargo de su enjuiciamiento (Maier, 2004). Además, en aquellos países en donde el porcentaje de población bajo la línea de pobreza es alto, los sistemas burocráticos no suelen tener suficiente personal para responder a la demanda. Por ende, y aunque este sistema refleja la predisposición del Estado a asumir la responsabilidad de la defensa pública, el sistema enfrenta dos importantes desafíos: sus potenciales usuarios no confían en el mismo y la oferta de defensores suele ser insuficiente para atender a una amplia población de bajos recursos ${ }^{1}$.

Lopez Puleio (2002) destaca que, en los últimos años, la Argentina ha sido testigo de un impresionante aumento en el número de casos que requieren servicios de defensores públicos a nivel federal. Mientras que, en 1994, el 64 por ciento de los casos penales contaban con la intervención de defensores públicos, dicho porcentaje aumentó a 68 por ciento en 1995, a 70 por ciento en 1996, y a 92 por ciento en el año 2000. Las estadísticas más recientes de la Defensoría General de la Nación indican que en el año 2008, el 79,07 por ciento de los casos atendidos por los Tribunales Orales Federales requirió la asistencia de defensores públicos, y el 87,13 por ciento de los casos de los Tribunales Federales Orales de las provincias (Ministerio Público de la Defensa 2009). Ese fue el último año en el que el Ministerio Público de la Defensa publicó ese dato. 
Recientemente los países europeos han desarrollado un tercer sistema en el cual los servicios jurídicos son provistos por asociaciones de abogados o por organizaciones autónomas de abogados pagadas por el Estado. Esto es, un sistema de asistencia legal privada subsidiado con fondos públicos. Este tercer sistema parecería resolver dos de los problemas que los otros sistemas no podían solucionar: los acusados pueden establecer una relación de confianza con sus abogados porque pueden elegir entre varios candidatos y, dado que los abogados reciben un pago por el servicio, es posible evitar los problemas asociados al carácter voluntario del sistema honorífico. Sin embargo, y en tanto este sistema también depende de la existencia de un financiamiento público adecuado, su éxito en países en desarrollo, en donde la demanda suele ser alta y los fondos públicos para su financiamiento bajos, también están cuestionados (Maier, 2004). Finalmente cabe destacar que, en los últimos tiempos, algunas ONG provinciales, clínicas legales universitarias, y asociaciones de abogados han empezado a ofrecer servicios jurídicos gratuitos a poblaciones de bajos recursos.

Cappelletti y Garth (1978) analizaron el problema del acceso a la justicia desde otro ángulo. Si bien tienen en cuenta los obstáculos que dificultan el acceso a los tribunales, su trabajo se concentró en los cambios que permitieron la ampliación de otras formas de acceso. En particular, identificaron tres grandes transformaciones. La primera, ocurrida en los años 60, implicó la reducción de las barreras institucionales, psicológicas y económicas que dificultaban el acceso. La segunda, tuvo lugar en los '70 y amplió quiénes podían ser representados y qué derechos podían exigirse ante los tribunales lo cual permitió que nuevos demandantes y temas ingresaran al sistema judicial. Finalmente, la tercera transformación implicó la incorporación de procedimientos alternativos para la resolución de los litigios. Las consecuencias de estas innovaciones fueron varias. Implicaron, por un lado, cambios en el significado y en la práctica del acceso. Acceso era no sólo derribar obstáculos sino también ampliar el tipo de reclamos y de derechos que podían realizarse y judicializarse. Otra consecuencia de estas transformaciones fue el aumento de la actividad judicial (Tate y Vallinder, 1995; Gauri y Brinks, 2008) y el consiguiente aumento de la necesidad de representación legal. Es más, en tanto estas modificaciones no derivaron en la eliminación del monopolio de la representación letrada en los procesos judiciales, cómo se presta asesoramiento y representación legal en forma gratuita continuó siendo un aspecto crítico del problema del acceso a la justicia, y un tema central en los debates sobre cómo se realiza el ideal de igualdad ante la ley en una democracia liberal. 


\section{Heterogeneidad en las Políticas y Federalismo en la Argentina}

¿Qué impacto tiene la estructura institucional federal en la forma en que se proveen servicios de asistencia y representación jurídica gratuita en las provincias argentinas? En los últimos años, la literatura y definiciones de federalismo crecieron notablemente (Linz, 1999; Stepan, 1999; Watts, 1999; Gibson, 2004; Gibson, 2013). Edward Gibson (2004), por ejemplo, sostiene que los federalismos suponen «la existencia de una unidad política nacional con niveles de gobierno duales (o múltiples), en donde cada uno de ellos tiene la autoridad exclusiva sobre áreas de política pública constitucionalmente predeterminadas, pero en las que solo un nivel de gobierno —el gobierno central- es internacionalmente soberano». Dahl nos recuerda que en los sistemas federales «algunos temas son de competencia exclusiva de ciertas unidades locales — cantones, Estados, provincias- y están constitucionalmente más allá de la autoridad del gobierno nacional, y que determinados temas están constitucionalmente fuera del alcance y de la autoridad de las unidades más pequeñas» (Dahl, 1986). La literatura reciente suele focalizarse en el impacto que la distribución y uso de los recursos fiscales tiene en la autonomía política de los Estados locales, en la estructura de los sistemas de partido locales, en las elecciones (Remmer y Gélineau, 2003; Calvo y Murillo, 2004), en la implementación de reformas económicas (Gibson y Calvo, 2000; Remmer y Wibbels, 2000) y en la democratización de los regímenes subnacionales (Giraudy, 2009; Gervasoni, 2010; Gervasoni, 2013). Un señalamiento común de esta literatura es que la distribución de los poderes fiscales condiciona la habilidad de los gobiernos locales para definir políticas propias o para resistir intervenciones políticas por parte del poder central. Sin desconocer la relevancia de este hallazgo, este artículo explora un aspecto diferente y complementario de esa discusión: el impacto que la estructura institucional del federalismo tiene en la distribución de bienes públicos entre jurisdicciones y en particular, en la distribución de la defensa pública entre las jurisdicciones subnacionales.

¿Cuáles son las características del sistema federal argentino? Argentina es un país federal, tiene veintitrés provincias, un gobierno autónomo en la Ciudad de Buenos Aires (CABA) y 1.922 municipalidades. Cada una de estas veinticuatro unidades subnacionales tiene su propia constitución, elige sus propios poderes ejecutivos y legislaturas provinciales, y organiza su propio poder judicial. La Constitución Nacional establece la primacía de la autoridad federal por sobre las provincias, pero también preserva los poderes de estas cuando no hay delegación explícita a la autoridad federal. El Artículo 5 de la Constitución Nacional otorga a las provincias el derecho de establecer sus propias constituciones, determinar sus propias reglas políti- 
cas, y a legislar y regular sus actividades legales — por ende, todas estas dimensiones pueden variar entre provincias-. Mientras que el Artículo 121 establece el principio general que define la autonomía legislativa de las provincias, otros establecen las áreas de política en las que las autoridades provinciales quedan subordinadas y otros en los cuáles tienen autonomía, o comparten poderes con las autoridades federales ${ }^{2}$. En consecuencia, mientras algunos artículos establecen la supremacía de las autoridades federales; otros definen el alcance de la subordinación y crean espacios de autonomía provincial.

Con respecto al tema específico de esta investigación, el Artículo 75 sección 12 estipula que las provincias tienen derecho a establecer tanto la organización de sus poderes judiciales como «los códigos procedimentales locales que regulan cómo las leyes serán implementadas a nivel provincial» (Gelli, 2005, mi énfasis). En otras palabras, las autoridades provinciales tienen la libertad de establecer el contenido específico de sus políticas judiciales. Si bien las provincias no pueden proteger menos que lo estipulado por la Constitución Nacional, tienen el derecho para redefinir qué significa un derecho y cómo el mismo será implementado, lo que da lugar a que lo que finalmente se termina protegiendo en cada jurisdicción varíe significativamente entre provincias. Dado que las provincias tienen poderes legislativos exclusivos sobre ciertas áreas de política pública, los actores y políticos locales desempeñan importantes roles en la definición del contenido específico que adquieren ciertos derechos, así como en la magnitud de los recursos asignados para su ejecución en cada distrito provincial. Una consecuencia de esto es la importante variación en el contenido y nivel de ejecución de las políticas entre provincias ${ }^{3}$. La autonomía legislativa provincial no explica, por sí sola, el contenido de las leyes provinciales, solo indica que existen condiciones institucionales que habilitan la variación de las mismas entre provincias. En

Los artículos 75, 99, 116, y 117 establecen las competencias que las provincias delegan a la legislatura, el poder ejecutivo y el poder judicial federales, mientras que los artículos 5, 75 (sección 12), y 122 explícitamente establecen las competencias reservadas para las provincias (Gelli, 2005).

3 La distribución de responsabilidades entre autoridades provinciales y federales varía ampliamente entre los sistemas federales latinoamericanos. En Brasil, por ejemplo, la autonomía legislativa a nivel estatal es baja en ciertas áreas de política pública. A pesar de que la Constitución de 1988 estableció que los estados tienen autonomía para tomar decisiones en áreas donde les fue explícitamente delegado a las autoridades federales, la cláusula 1 del artículo 22 redujo notablemente el alcance de la misma al enumerar las áreas de autoridad federal exclusiva (Souza, 2004). Si bien las variaciones en los niveles de protección de derechos también dependen de factores tales como la autonomía fiscal local, las capacidades estatales de los distritos o los recursos sociales y organizativos de los actores, se espera que la variación subnacional en la distribución de derechos esté positivamente correlacionada con la autonomía legislativa provincial. 
los hechos, el contenido específico que terminan adquiriendo las normas depende de la forma en que los actores locales operan e interactúan en el territorio. No obstante, en el caso argentino, donde los distritos tienen una gran autonomía legislativa, es altamente probable que la definición y la forma en que se provee defensa pública en las provincias sean muy heterogéneas.

Los párrafos anteriores señalan algunas de las complejidades y zonas grises que presenta la asignación constitucional de responsabilidades entre las autoridades provinciales y federales. Indican que existen algunas áreas en las que el gobierno federal prevalece por encima de las unidades provinciales, y otras en donde las preferencias judiciales y legislativas de las provincias se imponen. Si bien también existen áreas donde el poder central y provincial están en disputa, las autoridades provinciales cuentan con amplia autonomía para redefinir los contenidos específicos de los derechos, decidir cómo serán asignados los recursos y regular cómo se realizará su ejecución. Dado que las autoridades provinciales tienen un rol fundamental en la decisión e implementación de los derechos y las políticas, la próxima sección analiza la forma en que las provincias argentinas proveen defensa pública.

\section{4. ¿Cómo se provee defensa pública en las provincias argentinas?}

\section{a.Esquematizando las diferencias institucionales}

¿Cómo proveen defensa pública las provincias y el gobierno federal? Si bien los aspectos institucionales de los sistemas de defensa pública provincial no son suficientes para explicar el funcionamiento del sistema, los mismos permiten entender qué tipo de protección pueden esperar los acusados, qué restricciones encontrarán y a qué tipo de acciones podrán recurrir. En la Argentina, por ejemplo, hay provincias en las que los defensores públicos tienen autonomía para decidir qué casos tomarán, otras que permiten un amplio contacto de los acusados con sus defensores y otras en las que tanto la autonomía y el contacto están muy limitados.

La Constitución de 1853 (Artículo 18) estableció el «derecho a contar con representación legal en un juicio». Sin embargo, recién en 1878 la Corte Suprema de Justicia de la Nación asignó abogados a los acusados que no tenían recursos para contratar uno propio. En 1886, cuando se reguló el Artículo 18, se creó la Oficina del Defensor de Pobres en el poder judicial federal. Esto implicó la adopción del «sistema burocrático» que, más allá de algunos cambios, aún hoy sigue funcionando. Hasta la reforma constitucional de 1994, el servicio de defensa público, tanto a nivel federal como pro- 
vincial, era prestado por organismos auxiliares compuestos por abogados asociados a diferentes tribunales y jerárquicamente dependientes del poder judicial (Michelini, 2010; La Rosa, 2001). En 1994, la reforma constitucional creó el Ministerio Público Federal como «un órgano independiente con autonomía funcional y autarquía financiera, que tiene por función promover la actuación de la justicia en defensa de la legalidad de los intereses generales de la sociedad, en coordinación con las demás autoridades de la República. Está integrado por un procurador general de la Nación y un defensor general de la Nación y los demás miembros que la ley establezca» (Constitución de 1994, Artículo 120). En el año 2015 el Ministerio Público de la Defensa contaba con 203 defensores públicos federales distribuidos entre quince distritos judiciales con asiento en las provincias y la Ciudad Autonoma de Buenos Aires (Ministerio Público de la Defensa, 2015), quienes prestaba servicios de representación jurídica gratuitos a aquellos individuos que, habiendo sido acusados o condenados en casos penales federales, viven en la pobreza, son menores, o sufren discapacidades mentales (Ministerio Público de la Defensa). En 2008, el 79 por ciento de los casos recibidos por tribunales penales federales requirieron la asistencia del Ministerio Público de la Defensa (Ministerio Público de la Defensa 2009).

Dada la estructura federal argentina y que la Constitución establece que las provincias tienen derecho a organizar sus propios poderes judiciales, cada provincia, en los hechos, decide cómo se ofrece la defensa pública en su jurisdicción. En consecuencia, en la Argentina coexiste un sistema de defensa pública federal con veinticuatro sistemas provinciales ${ }^{4}$. Si bien existen contactos informales entre los defensores públicos federales y provinciales, el Ministerio Público de la Defensa de la Nación no tiene atribuciones institucionales para intervenir en la forma en que las defensorías provinciales prestan sus servicios. El único espacio institucional compartido, el Consejo Federal de la Defensa Pública de la República Argentina, se reúne anualmente pero no tiene atribuciones para imponer políticas a sus miembros ${ }^{5}$. Por ende, mientras todas las provincias prestan servicios de defensa pública, la forma específica en la que lo hacen depende de decisiones tomadas por sus legislaturas y poderes judiciales.

4 Antes de la Constitución de 1994, las provincias también decidían cómo garantizarían «el derecho a tener defensa al momento del juicio» (Artículo 18 de la Constitución de 1853), por lo tanto, es probable que las heterogeneidades que analiza este artículo ya estuvieran presentes.

5 Ver «Reglamento de Funcionamiento del Consejo Federal de la Defensa Pública de la República Argentina». www.mpd.gov.ar/uploads/documentos/Reglamento\%20Consejo $\% 20$ Federal.pdf. 
La Tabla 1 clasifica a las jurisdicciones provinciales según a) el grado de independencia de la defensa pública respecto del poder judicial y b) la accesibilidad a la defensa pública por parte de los acusados. La independencia de la defensa pública respecto del poder judicial mide si el Ministerio Público de la Defensa tiene la potestad para establecer programas y políticas especiales, para decidir la asignación de sus presupuestos o para desarrollar estrategias propias respecto a otras instituciones dentro del poder judicial. Sus subdimensiones son: a) si la Oficina de la Defensa Pública tiene poder para decidir políticas y presupuestos y b) si el Defensor Público provincial depende del Procurador Fiscal. Se supone que, si el poder para decidir políticas y presupuestos depende del Procurador, la Oficina de la Defensa tendrá menos capacidad para definir las políticas y temas en los que concentrarse y tampoco podrá tomar las decisiones presupuestarias que garanticen su implementación (López Puleio, 2002). Asimismo, si las cabezas de la procuración fiscal y la defensa no están diferenciadas, en tanto estas oficinas tienen funciones e intereses opuestos, es poco probable que la defensa pública pueda actuar autónomamente.

La accesibilidad a la defensa pública indica el nivel de dificultad que tienen los defendidos para obtener protección. Sus subdimensiones son: a) la permanencia de los defensores a través de las distintas instancias del proceso y b) la especialización de los defensores por materia judicial. Se espera que la accesibilidad sea más alta cuando el defensor público acompaña a un caso en todas las instancias, en tanto se presume que los cambios de defensores entre instancias aumentan los costos de transacción dado que un nuevo defensor estará obligado a informarse nuevamente los detalles del caso ${ }^{6}$. A su vez, y en relación a la «especialización por materia» se supone que la misma permite a los acusados acceder a un servicio de defensa más adecuado a sus necesidades legales.

6 Podría sostenerse que, si en la primera instancia el defensor fue ineficiente, un cambio de defensor en la instancia subsiguiente podría beneficiar al acusado. No obstante, prefiero suponer que la calidad de los defensores es similar entre los distintos niveles y que, por lo tanto, los costos de informarse sobre el caso son más costosos. 


\section{TABLA 1}

Regímenes institucionales de prestación de defensa pública en la Argentina (Leyes provinciales sancionadas entre 1972 y 2007)

\begin{tabular}{|c|c|c|c|c|c|}
\hline \multicolumn{2}{|c|}{$\begin{array}{l}\text { Independencia de la defensa } \\
\text { pública del poder judicial }\end{array}$} & \multicolumn{2}{|c|}{$\begin{array}{l}\text { Accesibilidad a la defensa } \\
\text { pública por los acusados }\end{array}$} & \multirow[b]{2}{*}{$\begin{array}{l}\text { E } \\
\text { Índice Institucional } \\
\text { de Defensa Pública } \\
\text { (sumatoria } \\
\text { columnas A,B,C, D) }\end{array}$} & \multirow[b]{2}{*}{ Jurisdicciones } \\
\hline $\begin{array}{l}\text { A } \\
\text { Poder para } \\
\text { tomar } \\
\text { decisiones } \\
\text { sobre } \\
\text { políticas y } \\
\text { presupuesto } \\
(\text { sí }=4, \\
\text { no }=0)\end{array}$ & $\begin{array}{l}\text { B } \\
\text { Distinción } \\
\text { entre los jefes } \\
\text { de la fiscalía y } \\
\text { los de los } \\
\text { defensores } \\
\text { públicos } \\
\\
(\text { sí }=3, \\
\text { no }=0)\end{array}$ & $\begin{array}{l}\text { C } \\
\text { Permanencia } \\
\text { de los } \\
\text { defensores a } \\
\text { través de las } \\
\text { instancias } \\
\\
(\text { sí }=2, \\
\text { no }=0)\end{array}$ & \begin{tabular}{|l|} 
D \\
Especialización \\
por tema \\
judicial \\
\\
$($ sí $=2$, \\
no $=0)$
\end{tabular} & & \\
\hline Sí & Sí & No & Sí & 9 & Salta \\
\hline No & Sí & Sí & Sí & 7 & $\begin{array}{l}\text { Mendoza, Río Negro, } \\
\text { Tucumán, Chubut Entre } \\
\text { Ríos, Córdoba }\end{array}$ \\
\hline No & Sí & No & Sí & 5 & $\begin{array}{l}\text { Santa Fe, Buenos Aires, } \\
\text { Formosa, San } \\
\text { Luis,CABA,Neuquén }\end{array}$ \\
\hline No & Sí & Sí & No & 5 & Jujuy, La Rioja \\
\hline No & No & Sí & Sí & 4 & $\begin{array}{l}\text { Chaco, La Pampa, } \\
\text { Catamarca, }\end{array}$ \\
\hline No & Sí & No & No & 3 & $\begin{array}{l}\text { Santa Cruz, Tierra del } \\
\text { Fuego }\end{array}$ \\
\hline No & No & No & Sí & 2 & \begin{tabular}{|l|}
$\begin{array}{l}\text { Corrientes, Misiones, } \\
\text { Santiagodel Estero* }\end{array}$ \\
\end{tabular} \\
\hline No & No & Sí & No & 2 & San Juan \\
\hline
\end{tabular}

Fuente: Leyes provinciales sancionadas entre 1972 y 2007.

Nota: Se aprobó una nueva ley de ministerio público en Santiago del Estero en diciembre de 2008. Dado que no ha sido promulgada, la tabla considera la organización estipulada en la Ley 3.752 de 1972.

La Tabla 1 muestra, en la columna E, el Índice Institucional de Defensa Pública (IIDP) y clasifica a los regímenes de provisión de defensa provincial según su nivel de independencia y accesibilidad. Las subdimensiones que miden «independencia» tienen mayor relevancia que las que miden «accesibilidad» porque se supone que la mayor independencia habilita a la Oficina de la Defensa Pública a tomar decisiones sobre políticas y presupuesto que a su vez impactan sobre la efectiva accesibilidad al sistema. Un sistema formalmente accesible pero subordinado presupuestariamente a otra oficina judicial puede perder, en los hechos, esa aparente cercanía (i.e. oferta de 
defensores menor a la necesaria, oficinas no distribuidas en el territorio). El IIDP tiene un rango muy amplio (entre 2 y 9 puntos), lo que ilustra la heterogeneidad legal existente entre los regímenes institucionales provinciales. Nueve jurisdicciones obtuvieron puntajes por debajo del punto medio de la escala, lo que indica que en esas provincias la independencia de la Oficina de la Defensa o los niveles de accesibilidad son «de jure» inferiores a los del resto de las jurisdicciones. Finalmente, cabe notar que el rasgo institucional menos frecuente es la autonomía de las Defensorías provinciales para tomar decisiones sobre las políticas y presupuestos sobre cuestiones relacionadas con la propia Oficina de la Defensa.

\section{TABLA 2}

Distribución de la independencia y accesibilidad de los regímenes de defensa pública provincial

\begin{tabular}{|c|c|c|c|c|c|}
\hline & & \multicolumn{3}{|c|}{$\begin{array}{l}\text { Independencia Defensa Pública } \\
\text { vis a vis Poder Judicial }\end{array}$} & \multirow{2}{*}{$\begin{array}{l}\text { Nro. de } \\
\text { provincias }\end{array}$} \\
\hline & & Alto* & Mediano $\dagger$ & Bajo $\neq$ & \\
\hline \multirow{3}{*}{ 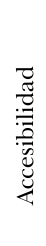 } & $\mathrm{Alto}^{\circ}$ & - & 6 & 3 & 9 \\
\hline & Mediano§ & 1 & 8 & 4 & 13 \\
\hline & Bajo\# & - & 2 & - & 2 \\
\hline \multicolumn{2}{|c|}{ Nro. de provincias } & 1 & 16 & 7 & 24 \\
\hline
\end{tabular}

* Los valores en las columnas A y B en la tabla 1 son sí.

† Los valores en las columnas A yB en la tabla 1 son sí-no o no-sí.

$\$$ Los valores en las columnas A y B en la tabla 1 son no.

- Los valores en las columnas C y D en la tabla 1 son sí.

$\S$ Los valores en las columnas C y D en la tabla 1 son sí-no o no-sí.

\# Los valores en las columnas C y D en la tabla 1 son no.

Fuente: Elaboración propia (2019).

La Tabla 2 clasifica a estos ocho regímenes según sus niveles de independencia y accesibilidad, y permite observar que, al menos en términos institucionales, los regímenes provinciales de defensa tienden a favorecer la accesibilidad por sobre la independencia. En 23 provincias las oficinas de defensores públicos tienen restricciones para diseñar sus propias políticas, y 
en 7 de ellas la subordinación a la oficina de la procuración pública es alta dado que la oficina de la defensa no cuenta con un director institucional. La Tabla 2 también indica que, en 9 de las 24 provincias, la accesibilidad al sistema es alta, tendencia que se explica principalmente por la presencia de defensores especializados antes que por la permanencia de los defensores a lo largo del proceso judicial.

Las Tablas 1 y 2 muestran las variaciones en los rasgos institucionales de los regímenes de prestación de defensa pública en las provincias argentinas. Esto es, más allá de las diferencias en la forma en que las provincias prestan servicios de defensa, existen significativas diferencias legales en el tipo de servicio de defensa al cual los ciudadanos de las distintas provincias pueden aspirar. Las próximas secciones analizan si las promesas de independencia y accesibilidad que hacen los regímenes institucionales provinciales condicen con la oferta efectiva de defensores, mapea la oferta de defensores existente y los factores que explican las variaciones en la oferta de defensores entre las provincias.

\section{b. ¿Cuál es la oferta de defensores}

y cómo se explica su distribución entre las provincias?

¿Cómo se distribuyen los defensores públicos entre las provincias y qué factores explican dicha distribución? Los datos sugieren que su oferta es muy desigual. Esto es, existe heterogeneidad en los regímenes institucionales, pero también en la oferta de defensores per cápita que ofrecen las provincias. Los dos tipos de heterogeneidad tienen consecuencias en la protección legal a la que pueden aspirar los ciudadanos de cada provincia. El Gráfico 1 muestra la oferta per capita de defensores públicos provinciales y federales en las provincias argentinas e indica que mientras Tierra del Fuego, Chubut y Neuquén son las provincias que ofrecen más defensa pública (federal y provincial) per capita; San Juan y Tucumán son la que menos defensores per capita tienen. El Gráfico 1 también permite observar que la relevancia de los defensores federales es mayor en las dos jurisdicciones más tardíamente provincializadas: $\mathrm{CABA}^{7}$ y Tierra del Fuego. ¿Es esta una manera adecuada de medir la oferta de defensores? Acaso, a la hora de medir la magnitud de la oferta ¿no habría que considerar también la superficie, litigiosidad o niveles de pobreza de cada jurisdicción?

A diferencia de lo que sucede en el resto de las jurisdicciones, la justicia de la Ciudad continúa bajo jurisdicción nacional. La ley Cafiero (24.588) sancionada en 1997, estableció que solo quedarían bajo jurisdicción de la Ciudad materias de vecindad, y relativas a la justicia contravencional y de faltas, contencioso-administrativa y tributaria local. Eso explica la relevancia que los defensores federales tienen en la jurisdicción. 


\section{GRÁFICO 1}

Oferta de Defensores Provinciales y Federales per cápita

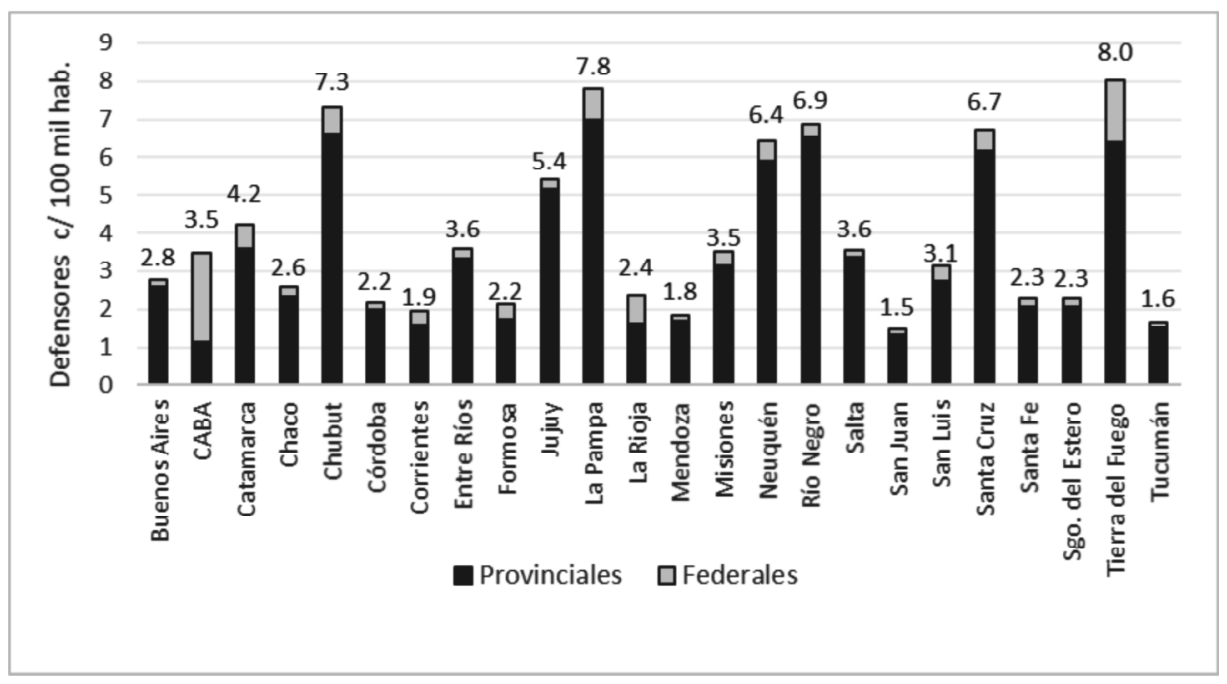

Fuente: Elaboración propia.

En la Argentina, a diferencia de lo que sucede en otros países, la oferta de defensores no se fija a partir de criterios predeterminados ${ }^{8}$. Cabe entonces preguntarse qué criterios utilizan las autoridades provinciales a la hora de definir la oferta de defensores en sus jurisdicciones. ¿Tienen en cuenta el tamaño (1) de la población provincial, (2) del territorio, (3) de la población vulnerable, o (4) los niveles de litigiosidad local? Podría argumentarse que las autoridades deberían considerar el tamaño de la población, en tanto en la medida en que cuanto mas grande sea, es probable que la actividad judicial aumente y consecuentemente también se incremente la cantidad de individuos que requieran asistencia de defensores públicos. También podría esperarse que, las autoridades provinciales tengan en cuenta la superficie de la jurisdicción, dado que, si el territorio es muy extenso, será necesario desplegar defensores a lo largo del territorio más allá de la densidad demográfica de la provincia. Es de esperar, entonces, que las provincias territorialmente más extensas tengan más defensores que las más pequeñas.

En los Estados Unidos, por ejemplo, los Estados calculan el número de defensores públicos a partir de criterios tales como la cantidad y complejidad de los casos que manejará cada abogado, el carácter rural o urbano de los casos (ver Departamento de Justicia de los Estados Unidos y The Spangenberg Group). Sin embargo, en tanto los criterios específicos que utiliza cada estado varían, la oferta efectiva de defensores también resulta desigual. 
Otro criterio que podría incidir en la oferta de defensores es la magnitud de la población de bajos recursos. Se supone que esta es la población que hace más uso de este servicio, en consecuencia, podría esperarse que cuanto mayor sea la población de bajos recursos, habrá más defensores para satisfacer la mayor demanda del servicio. Finalmente, puede suponerse que a la hora de definir la oferta de defensores, las autoridades también considerarán los niveles de litigiosidad local, dado que mayores niveles de litigiosidad sugieren que habrá una mayor demanda de los servicios de defensa pública9 ${ }^{9}$.

Los Gráficos 2 y 3 muestran cuál es la oferta de defensores en cada provincia cuando se tienen en cuenta la población, superficie y litigiosidad ${ }^{10}$. El Gráfico 2 ilustra en qué medida el número de defensores públicos provinciales observado en cada jurisdicción se aleja o se acerca a la oferta prevista cuando esta última se calcula teniendo en cuenta dichas dimensiones. Por su parte, el Gráfico 3 hace lo mismo, pero tiene también en cuenta a los defensores federales con asiento en cada provincia. Los dos gráficos muestran que existe una alta dispersión en la oferta de defensa pública entre las jurisdicciones provinciales. Sin embargo, cuáles son las jurisdicciones con mayor o menor déficit de defensores varía ligeramente según se considere a los defensores federales o no. Cuando, como en el Gráfico 2, solo se consideran los esfuerzos que hacen las provincias para brindar defensa pública, Córdoba, Mendoza y Santa Fe son las más deficitarias, y Neuquén, Jujuy y Misiones son las que hacen más esfuerzos. En tanto, cuando se considera a la oferta total de defensores (provinciales y federales), la oferta es mayor a la pronosticada en Neuquén, Chubut y Rio Negro, y notablemente menor a la prevista en Córdoba, Tucumán y Santiago del Estero. Como se mencionó anteriormente, la Ciudad Autónoma de Buenos Aires es un caso difícil de evaluar dada la peculiar división de tareas entre el ámbito federal y local. Si solo se considerara a lo defensores del distrito sería una de las jurisdicciones más deficitarias, sin embargo, cuando se considera a los defensores federales, se ubica entre los distritos que ofrecen mayor protección. Más allá de los cambios en las posiciones de cada provincia entre los resultados de ambos gráficos, el rasgo común entre los mismos es el alto nivel de dispersión interprovincial en la oferta efectiva de defensores.

$9 \quad$ La litigiosidad indica la contenciosidad de una población o la tendencia a concurrir a los tribunales (cantidad de causas ingresadas en una jurisdicción cada 100.000 habitantes).

10 Los gráficos estiman la diferencia entre la oferta observada de defensores y la oferta esperada según un modelo de regresión múltiple que incluye como variables explicativas la población, la extensión territorial de la provincial y el nivel de litigiosidad. 
Catalina Smulovitz

\section{GRÁFICO 2}

Defensores Públicos Provinciales (2015)

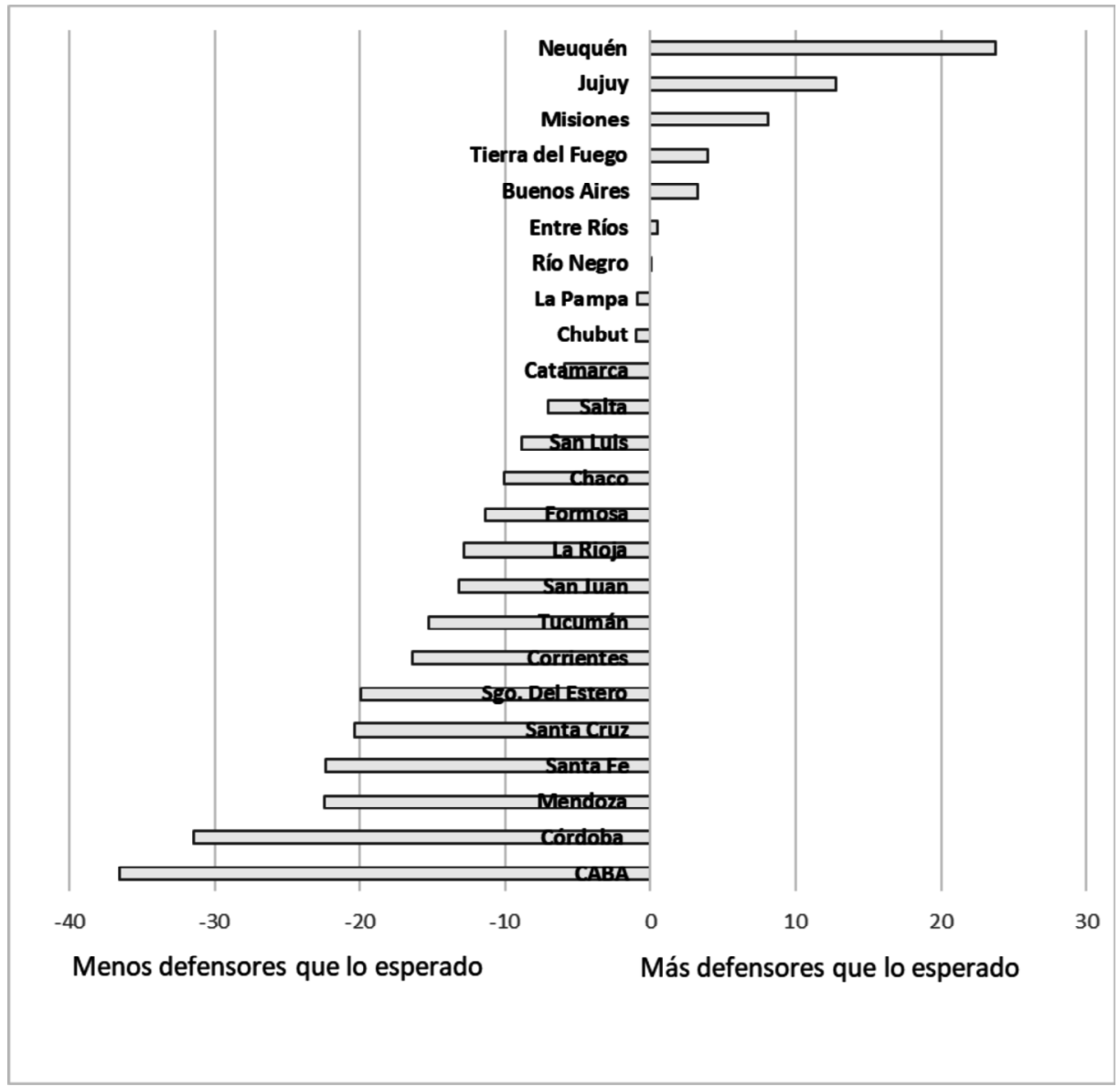

Fuente: JUFEJUS (2010) e INDEC (2019). Defensores públicos provinciales. Valores esperados según población, superficie y litigiosidad. 
Revista SAAP $\cdot$ Vol. 13, № 2

\section{GRÁFICO 3}

Defensores Públicos Provinciales y Federales (2015)



Fuente: JUFEJUS (2010) e INDEC (2019). Defensores públicos provinciales y federales. Valores esperados según población, superficie y litigiosidad.

¿Qué otras dimensiones pueden impactar sobre la oferta de defensores? Otras dos variables habitualmente mencionadas en la literatura son: el tamaño del mercado privado de abogados y el nivel de competencia política local. Se supone que el tamaño del mercado local privado de abogados afecta la oferta de defensores públicos porque cuando el mismo está saturado, los abogados de la actividad privada consideran que la defensa pública reduce sus chances de ser contratados por clientes particulares (Abel y Lewis, 1995). Esto es, consideran que, si la oferta de defensores públicos es alta, la demanda por sus servicios disminuye. Es de esperar entonces, que cuando 
la oferta de abogados privados es alta, dichos abogados o sus asociaciones intentarán contener la oferta de defensa pública o restringir la generosidad del régimen institucional a fin de proteger la demanda de sus servicios (entendida como el número de clientes o el valor de sus honorarios profesionales) ${ }^{11}$. En consecuencia, es de esperar que en las provincias en donde la cantidad de abogados particulares per cápita es alta, la oferta de defensores públicos sea baja, mientas que en aquellas en las que la oferta de abogados particulares es baja, el tamaño de la defensa pública será más grande.

¿Cuál podría ser el impacto de la competencia política sobre la oferta de defensores públicos? Puede suponerse que en aquellas provincias en las que la competencia política ${ }^{12}$ es alta, los políticos estarán más atentos a las necesidades de sus electores, y que por lo tanto podrían tener interés en impulsar mejoras en el sistema judicial tales como facilitar el acceso a la defensa pública. Es de esperar entonces que las provincias que poseen niveles más altos de competencia política, muestren una mayor oferta de defensores que las que tienen menores niveles.

Finalmente, cabe preguntarse si el régimen institucional de provisión de defensa pública tiene algún efecto sobre la oferta de defensores públicos. Desde una perspectiva normativa, podría suponerse que las provincias con regímenes institucionales más generosos tendrán una oferta más amplia de defensores públicos. Esto es, que cuando el IIDP (Ver Tabla 1) sea más alto, la oferta de defensores será mayor, en tanto podría suponerse que la provincia deberá asignar más personal para cumplir con esas promesas institucionales.

A fin de evaluar el impacto de cada una de estas variables sobre la oferta real de defensores, estimé una serie de modelos de regresión por mínimos cuadrados ordinarios (OLS, por su sigla en inglés). La Tabla 3 considera tres modelos, el Modelo 1, en donde la variable dependiente es la cantidad de defensores públicos provinciales que tenía una provincia en el año 2015, el modelo 2, que utiliza la misma variable dependiente pero que excluye a las observaciones de CABA, y el Modelo 3 cuya variable dependiente es la can-

11 En Argentina, los abogados pueden iniciar su práctica profesional luego de graduarse de una facultad de derecho oficialmente reconocida. Por ende, el número de abogados practicantes está relacionado con el número de graduados. Los Colegios de abogados no toman exámenes para determinar la admisión a la práctica. En consecuencia, para proteger la demanda y el precio de los servicios legales que ofrecen los abogados privados, los Colegios de abogados locales intentan influir sobre la regulación del acceso a los servicios jurídicos gratuitos. Si dicho acceso es amplio, la demanda de servicios privados mermará, y viceversa.

12 Competencia política se mide como contestación electoral ejecutiva. Se utiliza como indicador el margen de victoria promedio en las tres últimas rondas electorales en la categoría de gobernador. 
tidad de defensores públicos provinciales y federales que tenía cada jurisdicción en el $2015^{13}$.

A su vez, los modelos consideran las siguientes variables independientes: población y superficie de cada provincia, tamaño del mercado provincial privado de abogados, nivel de litigiosidad y de necesidades básicas insatisfechas, grado de competencia política y régimen institucional de provisión de defensa pública provincial medido a partir del IIDP. Los resultados son presentados en la Tabla 3. Dado el pequeño número de observaciones, los hallazgos tienen un carácter preliminar y un propósito exploratorio.

¿Qué muestran las estimaciones de la Tabla 3? En primer lugar, sus resultados sugieren que la oferta de defensores públicos provinciales está relacionada con una de las dimensiones administrativas, como es el tamaño de la población. Los modelos muestran que, manteniendo constantes al resto de las variables, un aumento de 100 mil habitantes en la población está asociado con un aumento de entre 2.8 (modelo 1) y 3.1 (modelo 2 ) defensores públicos provinciales, o 2.6 defensores provinciales y federales (modelo 3). Las estimaciones también muestran que en ninguno de los tres modelos la superficie de la provincia resulta ser un factor determinante del tamaño de la defensa pública.

Los Modelos 1 y 2 confirman las expectativas respecto del impacto del tamaño del mercado privado de abogados en la oferta de defensores. Dichos modelos muestran que el mercado de abogados privado tiene un efecto negativo y estadísticamente significativo sobre la oferta de defensores provinciales, cuando la cantidad de abogados privados aumenta en aproximadamente 1400, el número de defensores públicos baja en 1. El efecto no se observa en el Modelo 3, que considera a los defensores federales con asiento en provincia, dado que la capacidad de los abogados privados y de los Colegios de abogados locales para presionar e incidir sobre las autoridades federales en decisiones relacionadas con la oferta de defensores públicos federales es probablemente menor que la que poseen para incidir en decisiones y autoridades relacionadas con la provisión de defensa pública en su propio distrito. Las autoridades provinciales no deciden la oferta de defensores federales con asiento en provincia, y la capacidad de los abogados privados y Colegios locales para presionar e incidir sobre las políticas de recursos humanos de la justicia federal es menor que la que tienen para hacerlo en su propia jurisdicción.

13 Si bien los defensores federales con sede en provincia actúan en otro tipo de delitos (Ver cita 8) su inclusión en el Modelo 3 permite observar la oferta total de defensores a la que acceden los ciudadanos en las provincias, e incluir en la comparación y estimaciones a CABA. Si en el Modelo 3 no se incluyera a los defensores federales, la provisión de defensa en CABA resultaría subestimada o CABA debería ser eliminada de las estimaciones como sucede en el Modelo 2. Dado que las tres soluciones para medir la oferta de defensores pueden ser consideradas problemáticas, decidí incluir los resultados de las tres estimaciones. 


\section{TABLA 3}

\section{Regresión OLS de oferta de defensores públicos}

\begin{tabular}{|c|c|c|c|}
\hline & Modelo 1 & Modelo 2 & Modelo 3 \\
\hline Variables & $\begin{array}{l}\text { Defensores públicos } \\
\text { provinciales }\end{array}$ & $\begin{array}{l}\text { Defensores públicos } \\
\text { provinciales } \\
\text { (Sin CABA) }\end{array}$ & $\begin{array}{l}\text { Defensores públicos } \\
\text { provinciales y federales }\end{array}$ \\
\hline \multirow[t]{2}{*}{ Población } & $2.8006^{* * * *}$ & $3.1275 * * *$ & $2.6460 * * *$ \\
\hline & $(0.1592)$ & $(0.3289)$ & $(0.1788)$ \\
\hline \multirow[t]{2}{*}{ Superficie $(\mathrm{km} 2)$} & 0.0696 & 0.0743 & 0.0647 \\
\hline & $(0.0538)$ & $(0.0535)$ & $(0.0604)$ \\
\hline \multirow[t]{2}{*}{ Abogados } & $-0.0007 * * *$ & $-0.0016^{*}$ & \begin{tabular}{|l|}
0.0002 \\
\end{tabular} \\
\hline & $(0.0003)$ & $(0.0008)$ & $(0.0003)$ \\
\hline \multirow[t]{2}{*}{ Litigiosidad } & -0.0105 & -0.0098 & -0.0127 \\
\hline & $(0.0075)$ & $(0.0075)$ & \begin{tabular}{|l|}
$(0.0084)$ \\
\end{tabular} \\
\hline \multirow[t]{2}{*}{ NBI } & -0.2107 & -0.2018 & -0.2498 \\
\hline & $(0.7511)$ & $(0.7446)$ & $(0.8435)$ \\
\hline \multirow[t]{2}{*}{ Competencia Política } & -0.3153 & -0.4173 & -0.2639 \\
\hline & $(0.3651)$ & $(0.3730)$ & $(0.4100)$ \\
\hline \multirow{2}{*}{ IIDP } & 0.222 & -0.0199 & 0.4727 \\
\hline & \begin{tabular}{|l|}
$(1.5107)$ \\
\end{tabular} & $(1.5128)$ & $(1.6966)$ \\
\hline \multirow[t]{2}{*}{ Constante } & 14.419 & \begin{tabular}{|l|}
16.6416 \\
\end{tabular} & 16.29003 \\
\hline & (19.9036) & (19.8272) & $(22.3511)$ \\
\hline $\mathrm{R}^{2}$ & 0.9836 & 0.9849 & 0.9740 \\
\hline Adj $R^{2}$ & 0.9764 & 0.9778 & 0.9819 \\
\hline Root MSE & 13.469 & 13.351 & 15.125 \\
\hline $\mathrm{F}$ & 137.13 & 139.63 & 123.91 \\
\hline Prob $>$ F & 0.0000 & 0.0000 & 0.0000 \\
\hline $\mathrm{N}$ & 24 & 23 & 24 \\
\hline
\end{tabular}

Errores estándar entre paréntesis. * $\mathrm{p}<.1 ; * * \mathrm{p}<.05 ; * * * \mathrm{p}<.01$

Variables: Defensores públicos provinciales: número de defensores públicos provinciales (Ju.Fe.Jus, 2015). Defensores provinciales y federales: número de defensores públicos provinciales y federales en la jurisdicción (Ju.Fe.Jus y CSJN, 2015). Población: Población provincial estimada cada 100 mil habitantes (INDEC, 2015) Superficie: superficie continental provincial en KM2 $(1=1000 \mathrm{~km} 2)$ (INDEC). Litigiosidad: cantidad de causas ingresadas en los poderes públicos provinciales cada 10 mil habitantes (Ju.Fe.Jus, 2015. Misiones, 2014. Santa Cruz, 2010). NBI: Hogares con Necesidades Básicas Insatisfechas (INDEC, 2010). Abogados: cantidad de abogados (Ju.Fe.Jus, 2015. San Juan: 2014). Competencia política: margen de victoria promedio en elecciones ejecutivas provinciales (DINE, 20032015). Índice institucional de defensa pública: medida de la independencia y equidad del régimen institucional de defensa pública.

Fuente: Elaboración propia (2019). 
Los modelos también muestran que las variables relacionadas con necesidades de los potenciales usuarios de la defensa pública (poblaciones con menores recursos o más litigiosas) no afectan la oferta de defensores de una jurisdicción. El tamaño de la población con necesidades básicas insatisfechas y el grado de litigiosidad no tienen efectos estadísticamente significativos sobre la oferta. Estos resultados sugieren que la oferta de defensores públicos esta principalmente determinada por consideraciones administrativas o burocráticas, como la población, antes que por las necesidades de los ciudadanos. Los resultados de la Tabla 3, también indican que la competencia política tampoco tiene un efecto estadístico significativo sobre la oferta de defensores públicos. Una probable explicación para este resultado es que los beneficios electorales de las intervenciones que conducen a incrementos en la oferta de defensa pública sean probablemente limitados y difíciles de realizar. A menos que un partido tenga una motivación ideológica para promover incrementos en la oferta de defensores, los mismos no cuentan con incentivos de corto plazo para hacerlo. Los beneficios del aumento en la oferta de defensa pública son difusos y es difícil para un partido demostrar el crédito por su autoría.

Finalmente, los tres modelos muestran que el régimen institucional de provisión de defensa (medido con el IIDP; ver Tabla 1) tampoco tiene un impacto estadísticamente significativo sobre el tamaño de la defensa pública. ¿’Por qué la oferta de defensores es independiente del régimen institucional de defensa de cada jurisdicción? Es probable que estas dos variables sean independientes porque los incentivos que enfrentan los legisladores cuando legislan sobre derechos (régimen institucional de defensa) y cuando asignan recursos económicos para realizarlos (oferta de defensores) son distintos. Cuando se legisla sobre ampliación de derechos los beneficios simbólicos que obtiene el electorado ante este tipo de decisiones son de realización inmediata; los créditos políticos de dichas decisiones son identificables y de fácil apropiación, y los costos económicos que implicarán la implementación de las mismas son postergables en tanto dependen de decisiones presupuestarias que tendrán lugar en otro momento y con otros actores (Smulovitz, 2015a). En cambio, cuando los legisladores discuten los presupuestos necesarios para realizar un derecho (i.e. asignación de recursos para aumentar oferta de defensores) enfrentan otro tipo de incentivos y consideraciones que vuelven sus decisiones más cautas y menos generosas. A la hora de decidir presupuestos, los beneficios de satisfacer una demanda particularista (i.e. aumentar defensa pública) se diluyen ante la diversidad de presiones y demandas que enfrentan y despliegan el resto de los actores que aspiran a ser satisfechos. En esas circunstancias, la conducta prudencial del legislador es satisfacer en algo a la mayor parte de los actores demandantes antes que garantizar la satisfacción selectiva de un grupo particular. Es de esperar, 
entonces, que cuando los legisladores definen asignaciones presupuestarias, $y$, a diferencia de lo que sucede cuando definen el contenido de derechos de grupos específicos, los legisladores prefieran satisfacer aquellas demandas que pueden distribuir beneficios identificables en un público amplio antes que aquellas que solo distribuyen beneficios a un grupo particular y pequeño. En otras palabras, la independencia entre el régimen institucional de la defensa y la oferta efectiva de defensores es atribuible a los distintos incentivos que enfrentan las autoridades políticas en el momento en que tienen que decidir derechos o gastos. Los legisladores saben que tienen beneficios políticos a corto plazo si aprueban leyes generosas en derechos, y también saben que podrán evitar los costos de la implementación de los mismos en tanto las decisiones presupuestarias tendrán lugar en otro momento, y son eventualmente postergables (Smulovitz, 2015b). En consecuencia, es de esperar que el contenido de las leyes sea más generoso que los presupuestos que luego se asignan para su ejecución.

\section{Conclusiones}

El artículo muestra que tanto los regímenes institucionales de defensa pública como la oferta de defensores varían entre las provincias argentinas. Mientras que la heterogeneidad institucional indica que la protección a la que los individuos pueden aspirar varía según la provincia en la que residen, la heterogeneidad en la oferta de defensores revela que el acceso a la justicia es desigual entre provincias y entre los ciudadanos. Esto es, en la Argentina el acceso a la defensa pública es «de jure» $\mathrm{y}$ «de facto» desigual. El trabajo también muestra que la oferta efectiva de defensores públicos no depende de las características institucionales de los regímenes de defensa pública ni de las necesidades de los potenciales usuarios del servicio o del nivel de la competencia política. Por el contrario, la oferta de defensores está relacionada con consideraciones administrativas, tales como el tamaño de la población provincial, y el tamaño del mercado local de abogados privados. Estos hallazgos parecerían confirmar, que las amplias capacidades legislativas que el diseño institucional del federalismo argentino otorga a las autoridades locales para decidir sobre sus sistemas legales y sobre la asignación de recursos para volverlos operables, habilitan la emergencia de importantes diferencias en la forma en que se protegen derechos y se ofrece defensa pública en cada jurisdicción.

En relación a la literatura sobre acceso a la justicia, los hallazgos del artículo sugieren que, además de los obstáculos relacionados con el capital social de los actores, estos estudios también deberían considerar el impacto del federalismo sobre el acceso. El trabajo muestra que, en estos contextos, 
el acceso a la justicia es desigual, no solo por el carácter privilegiado de los actores involucrados, sino también por las capacidades que tiene cada jurisdicción para decidir qué tipo de protección y qué oferta de servicios brindará. Más allá de las razones pragmáticas o normativas que justifican la autonomía legislativa provincial en los sistemas federales, el trabajo muestra que dicha autonomía también puede derivar en una amplia desigualdad interprovincial. En consecuencia, si bien no se puede desestimar el impacto que los recursos de los actores tienen en la distribución de una política pública, el estudio demuestra que la estructura institucional federal puede convertirse en otra fuente de desigualdad y un obstáculo adicional al acceso.

El artículo también sugiere nuevas áreas de investigación. Sabemos que «el federalismo significa desigualdad» (Wildavsky, 1985) y este trabajo analizó por qué y cómo se produce esta desigualdad en un entorno federal particular. No obstante, quedan todavía muchas preguntas por responder. Por ejemplo, ¿por qué esta variación entre distritos es más significativa en algunos países federales que en otros? ¿qué determina el grado de heterogeneidad de los distintos sistemas federales, su estructura institucional específica, las características de los actores políticos locales, la naturaleza de las políticas implicadas, o la existencia de mecanismos de compensación y coordinación para abordar estas desigualdades? Estas preguntas requieren consideración comparativa y empírica. Sabemos que el federalismo implica desigualdad, pero todavía desconocemos por qué algunos países federales son más desiguales que otros.

La heterogeneidad observada también permite reflexionar sobre las consecuencias normativas que los federalismos tienen sobre la igualdad legal en las democracias liberales. Sabemos que la heterogeneidad entre las unidades que componen un país federal puede ser justificada en nombre de la autonomía de las unidades, o en el hecho de que permite experimentar e innovar respuestas políticas en el territorio. Sin embargo, la heterogeneidad en la definición del contenido de ciertas políticas públicas muestra que el federalismo tambien puede dar lugar a desigualdades legales entre los ciudadanos de una misma unidad política federalmente organizada. Si la definición del contenido específico de lo que legalmente puede aspirar un ciudadano depende del distrito particular en el que vive, puede argumentarse que el federalismo promueve no solo autonomía y experimentación, sino que, en ocasiones también puede conspirar contra una característica central del Estado de derecho: la igualdad ante la ley. Si ese es el caso, necesitamos considerar qué significa la igualdad ante la ley en sistemas federales y cómo puede lograrse. ¿Existen, acaso, situaciones en las que la desigualdad ante la ley es compatible con la democracia? ¿Qué argumento justifica que la desigualdad legal sea un resultado aceptable en países democráticos federales? Si dicho resultado fuese aceptable, ¿̇uánta desigualdad es tolerable, es decir, cuán desigual puede ser 
el trato legal de los ciudadanos antes de que dicha desigualdad comprometa el estado de derecho en una democracia liberal? Este artículo no responde a esta última serie de preguntas. Su propósito fue evaluar la forma en que se prestan los servicios de defensa pública en un sistema de gobierno federal determinado. Sin embargo, los resultados empíricos del mismo dieron lugar a este conjunto de preguntas que también exigen una respuesta.

\section{Referencias bibliográficas}

Abdulhadi, A. (2016). Disputas faccionales y cortes judiciales en las provincias argentinas: Misiones bajo el Frente Renovador (2003-2011). En Revista SAAP, 10 (2).

Abdulhadi, A. (2019). Cortes judiciales y fortalecimiento de la democracia. Una agenda abierta. En Tramas, 7, junio.

Abel, R. L., y P. S. C. Lewis. (Eds.) (1995). En Lawyers in Society: An Overview. Berkeley: University of California Press.

Bergoglio, M. I. (2007). New paths toward judicial legitimacy: the experience of mixed tribunals in Córdoba. En Sw. JL and Trade Am., 14.

Bill Chavez, R. (2004). The Rule of Law in Nascent Democracies: Judicial Politics in Argentina. Stanford: Stanford University Press.

Calvo, E., y V. Murillo (2004). Who Delivers? Partisan Clients in the Argentine Electoral Market. En American Journal of Political Science, 48 (4).

Cappelletti, M., y B. Garth (Eds.). (1978). En Access to Justice: A World Survey. Milán: Sijhoff/Giufre.

Castagnola, A. (2010). La Diversidad Institucional de los Poderes Judiciales Provinciales en Argentina desde una Perspectiva Histórica. En Postdata, 15 (2).

Dahl, R. (1986). A Preface to Economic Democracy. Berkeley: University of California Press.

Departamento de Justicia de los Estados Unidos y The Spangenberg Group (2001). En Keeping Defender Workloads Manageable. Bureau of Justice Programs. Washington: Departamento de Justicia de los Estados Unidos.

Diaz Cayeros, A. (2006). Federalism, Fiscal Authority, and Centralization in Latin America. Cambridge: Cambridge University Press.

Dulitzky, A. (2007). Implementación del Derecho Internacional de los Derechos Humanos en los Sistemas Federales: El Caso de la Convención Americana sobre Derechos Humanos y la República Argentina. En Abramovich, V., A. Bovino. y C. Courtis (Eds.) La Aplicación de los Tratados sobre Derechos Humanos en el Ámbito Local: La Experiencia de una Década. Buenos Aires: Corporación Gráfica.

Dulitzky, A. (2009). El Sistema Interamericano de Derechos Humanos. En Ollé Sesé, M., L. Acebal Monfort, y N. García Sanz (Eds.) Derecho Internacional de los Derechos Humanos: Su Vigencia para los Estados y para los Ciudadanos. Barcelona: Anthropos Editorial. 
Epp, C. (1998). The Rights Revolution: Lawyers, Activists and Supreme Courts in Comparative Perspective. Chicago: University of Chicago Press.

Frias, S. (2008). Measuring Structural Gender Equality in Mexico: A State Level Analysis. En Social Indicators Research, 88 (2).

Frias, S. (2010). Resisting Patriarchy within the State: Advocacy and Family Violence in Mexico. En Women's Studies International Forum, 33 (6).

Galanter, M. (1974). Why the 'Haves' Come Out Ahead: Speculations on the Limits of Legal Change. En Law and Society Review, 9 (1).

Garavano, G. (2006). Información y Justicia II. Datos sobre la Justicia Argentina. Buenos Aires: Unidos por la Justicia Asociación Civil.

Garavano, G. (2011). Información y Justicia III. Datos sobre la Justicia Argentina. Buenos Aires: Unidos por la Justicia Asociación Civil.

Gauri, V., y D. Brinks (Eds.). (2008). Courting Social Justice: Judicial Enforcement of Social and Economic Rights in the Developing World. Nueva York: Cambridge University Press.

Gelli, M. A. (2005). Constitución de la Nación Argentina: Comentada y Concordada. Buenos Aires: La Ley.

Gervasoni, C. (2010). A Rentier Theory of Subnational Regimes: Fiscal Federalism, Democracy and Authoritarianism in the Argentine Provinces. En World Politics, 62 (2).

Gervasoni, C. (2013). Transferencias federales y competitividad electoral: La ventaja oficialista de gobernadores en provincias rentísticas (1983-2011). En Abraham, M.A., et al, Consecuencias económicas y políticas del federalismo fiscal argentino. La Plata: Universidad Nacional de La Plata-Facultad de Ciencias Económicas.

Gibson, E. y E. Calvo (2000). Federalism and Low Maintenance Constituencies: Territorial Dimensions of Economic Reform in Argentina. En Studies in Comparative International Development, 35 (3).

Gibson, E. (Ed) (2004). Federalism and Democracy in Latin America. Baltimore: Johns Hopkins University Press.

Gibson, E. L. (2013). Boundary control: Subnational authoritarianism in federal democracies. Cambridge: Cambridge University Press.

Giraudy, A. (2009). Subnational Undemocratic Regime Continuity after Democratization: Argentina and Mexico in Comparative Perspective. [Disertación de PhD., University of North Carolina].

Gunst, R. (1983). Regression Analysis with Multicollinear Predictor Variables: Definition, Detection, and Effects. En Communications in Statistics: Theory and Methods, 12 (19).

Henderson, D., y D. Denison (1989). Stepwise Regression in Social and Psychological Research. En Psychological Reports, 64.

Junta Federal de Cortes y Superiores Tribunales de Justicia de las Provincias Argentinas y Ciudad Autónoma de Buenos Aires (JUFEJUS). (2010). En Estadísticas Judiciales de las Provincias Argentinas y de la Ciudad Autónoma de Buenos Aires, 2008. 
Junta Federal de Cortes y Superiores Tribunales de Justicia de las Provincias Argentinas y Ciudad Autónoma de Buenos Aires (JUFEJUS). (2011). En Estadísticas Judiciales de las Provincias Argentinas y de la Ciudad Autónoma de Buenos Aires, 2009. Kritzer, H., y S. Silbey (Eds.). (2003). In Litigation Do the «Haves» Still Come Out Ahead?, Stanford: Stanford University Press.

La Rosa, M. (2001). La Defensa Pública Oficial en su Inserción Constitucional como Custodio y Garante de los Derechos Individuales. Jurisprudencia Argentina.

Lieberman, E. (2005). Nested Analysis as a Mixed-Method Strategy for Comparative Research. En American Political Science Review, 99 (3).

Linz, J. (1999). Democracia, Multinacionalismo y Federalismo. En Revista Española de Ciencia Política, 1 (1).

Lopez Puleio, M. F. (2002) Justicia Penal y Defensa Pública. La Deuda Pendiente. En Revista Latinoamericana de Política Criminal Pena y Estado, 5, 23-48.

Macor, D. y C. Tcach (Eds.). (2003). La invención del peronismo en el interior del país. Santa Fe: Universidad Nacional del Litoral.

Maier, J. (2004). Derecho Procesal Penal, Vol. 2. Buenos Aires: Editores del Puerto.

Michelini, J. (2010). Sobre la Defensa Pública de Cara al Bicentenario de la Revolución de Mayo. Recuperado de: www.mpd.gov.ar/articulo/index/articulo/concurso-la-defensa-publica-y-el-bicentenario-1000.

Ministerio Público de la Defensa. (2009). Defensoría General de la Nación: Informe Anual 2007-2009. Buenos Aires: Defensoría General de la Nación.

O’Donnell, G. (1993). Acerca del Estado, la Democratización y Algunos Problemas Conceptuales. Una Perspectiva Latinoamericana con Referencias a los Países Postcomunistas. En Desarrollo Económico, 33 (130).

Pérez Perdomo, R. (2003). Latin American Lawyers: A Historical Introduction. Stanford: Stanford University Press.

Remmer, K. y F. Gélineau (2003). Subnational Electoral Choice: Economic and Referéndum Voting in Argentina (1983-1999). En Comparative Political Studies, 36 (7).

Remmer, K. y E. Wibbels (2000). The Subnational Politics of Economic Adjustment: Provincial Politics and Fiscal Performance in Argentina. En Comparative Political Studies, 33 (4).

Rhode, D. (2004). Access to Justice. Nueva York: Oxford University Press.

Shapiro, M. (1981). Courts: A Comparative and Political Analysis. Chicago: University of Chicago Press.

Smulovitz, C. (2015a). Legal inequality and federalism: Domestic violence laws in the Argentine Provinces. En Latin American Politics and Society, 57.

Smulovitz, C. (2015b) ¿Quién Paga por los Derechos en las Provincias Argentinas? El Caso de las Leyes de Violencia Familiar. En Desarrollo Económico, 55 (216), septiembre-diciembre.

Smulovitz, C. (2019). Public Defense and Access to Justice in a Federal Context: Who gets what, and How in the Argentinian Provinces. En Ingram M., y. Kapiszewski, 
D (Eds.), Beyond High Courts. The Justice Complex in Latin America. Notre Dame: Notre Dame University Press.

Souza, C. (2004). Subnational Constitutionalism in Brazil: Taxing, Spending, and Borrowing. [Paper presentado en Federalism and Subnational Constitutions: Designs and Reform Conference. Bellagio, Italia.]

Stepan, A. (1999). Federalism and Democracy: Beyond the US Model. En Journal of Democracy, 10 (4).

Stepan, A. (2004). Electorally Generated Veto Players in Unitary and Federal Systems.

En Gibson, E. (Ed.). Federalism and Democracy in Latin America. Baltimore: Johns Hopkins University Press.

Tate, N. y T. Vallinder (Eds.). (1995). The Global Expansion of Judicial Power. Nueva York: New York University Press.

Watts, R. (1999). Comparing Federal Systems. Montreal: McGill-Queen's University Press. Wildavsky, A. (1985). Federalism Means Inequality. En Society, 22 (2).

Wilson, B., y J. C. Rodriguez Cordero (2006). Legal Opportunity Structures and Social Movements: The Effects of Institutional Change on Costa Rican Politics. En Comparative Political Studies, 39 (3).

\title{
Palabras clave
}

federalismo — defensa pública — acceso a la justicia — igualdad de derechos - política subnacional

\begin{abstract}
The article compares the ways in which Argentine provinces provide free legal services and analyzes the factors that account for the differences in their provision. It claims that public defenders' provision and access to justice are quite heterogeneous among jurisdictions, since Argentine federalism grants great legislative power to provinces to define their local legal system. The article describes the variation in the way provinces allocate public defenders and analyzes if the latter can be attributed to administrative factors, local needs, the supply of private lawyers or the levels of political competition. Empirical results reveal that the manner in which provinces allocate public defenders is not related to the population needs, but instead to administrative factors and the size of the local market of private lawyers.
\end{abstract}

\section{Keywords}

federalism - public defense — access to justice — equal rights — subnational policy 